\title{
La Lisozima Como Conservante Natural En La Elaboración De Quesos Semi-Maduros
}

\author{
Diana Villa \\ Miguel Osorio \\ Teresita Mejía \\ Norma Toledo \\ Escuela Superior Politécnica de Chimborazo \\ Juan Haro \\ Escuela de Post Grado/ IPEC \\ Luis Quevedo \\ Escuela Superior Politécnica de Chimborazo
}

doi: 10.19044/esj.2017.v13n24p1 URL:http://dx.doi.org/10.19044/esj.2017.v13n24p1

\begin{abstract}
In the IASA II Molestina Dairy Plant, different levels of lysozyme were evaluated as a natural preservative $(5,10$ and 15\%). This replaces the chemical preservative (sorbic acid E300) in the production of Andean cheese ("semimaduro"). By using 256 liters of milk divided into 32 experimental units of 4 liters each, the experimental results were subjected to analysis of variance and separation of means by the Waller-Duncan test. It also went through the Test of Rating Test for organoleptic characteristics. Determining the levels of lysozyme did not affect the physico- chemical properties of cheese. It presents an average content of $37.46 \%$ moisture, $26.53 \%$ protein, $25.53 \%$ fat, $5.65 \%$ ash, and a slightly acidic $\mathrm{pH}$ (6.04). The preference of consumers according to the organoleptic characteristics shows that there were no differences between cheeses, receiving a score of Very Good. The initial microbiological tests identified the absence of total coliforms, molds and yeasts, which is in contrast to the 21 days of storage (shelf life). Lower amounts of microorganisms increases the levels of lysozyme, and provides better Employment answers level of 15\%. The highest yield (10.25\%), as well as lower production costs (4.89 USD per kg), were obtained when we prepared the semi-mature cheese with $15 \%$ of lysozyme in place of chemical preservatives. So this level is recommended in the development of Andean type cheeses.
\end{abstract}

Keywords: Preservative, Dairy, Plant, Cheese, Lysozyme 


\section{Resumen}

En la Planta de Lácteos Molestina de la ESPE (IASA II), se evaluó distintos niveles de Lisozima como conservante natural (5, 10 y $15 \%)$, en reemplazo del conservante químico (ácido sórbico E300), en la elaboración de queso tipo Andino (semi-maduro), utilizándose 256 litros de leche, divididos en 32 unidades experimentales, de 4 litros cada una, los resultados experimentales se sometieron a análisis de varianza y separación de medias mediante la prueba de Waller- Duncan, así como la prueba de Rating Test para las características organolépticas. Determinándose que los niveles de lisozima no afectaron las propiedades físico-químicas del queso, presentando contenidos promedios de $37.46 \%$ de humedad, $26.53 \%$ de proteína, 25.53 $\%$ de grasa y $5.65 \%$ de cenizas, un $\mathrm{pH}$ ligeramente ácido (6.04). La preferencia de los consumidores según las características organolépticas, determinan que no hubo diferencias entre los quesos, recibiendo todas, una calificación de Muy buena. Los análisis microbiológicos iniciales determinaron la ausencia de coliformes totales, así como mohos y levaduras, en cambio a los 21 días de almacenamiento (vida de anaquel), se determinó cantidades de microorganismos que disminuyen a medida que se incrementa los niveles de lisozima, presentando mejores respuestas el empleo del nivel $15 \%$. Los mayores rendimientos $(10.25 \%)$, así como los menores costos de producción (4.89 USD por $\mathrm{kg}$ ), se obtuvieron cuando se elaboró el queso semi-maduro con el $15 \%$ de lisozima en reemplazo del conservante químico, por lo que se recomienda utilizar este nivel en la elaboración de quesos tipo Andino.

Palabras-claves: Conservante, Lácteos, Planta, Quesos, Lizosima

\section{Introduction}

La demanda de alimentos de alto valor nutritivo está restringida principalmente por la falta de educación, poca disponibilidad de alimentos y falta de ingresos. Los alimentos como la carne, huevos, leche y sus derivados, que contienen proteína de origen animal, son escasos y su elevado costo no permite que sean consumidos muy frecuentemente.

Generalmente, en las pequeñas empresas del Ecuador, las condiciones del ordeño, transporte y conservación de la leche no se encuentran dentro de los parámetros adecuados, esto es causado por varios factores, entre los mas significativos es posible citar la falta de capacitación, no cuentan con los recursos técnicos apropiados, o simplemente existe un marcado descuido en el tratamiento adecuado de la leche. Las causas antes citadas han llevado a las pequeñas y medianas queseras rurales a trabajar con materias primas (leche) de mala calidad acompañando a esto la ausencia de 
buenas prácticas de manufactura que se deberían aplicar al momento del trabajo.

La leche y los productos lácteos, debido a su composición química y a su elevada actividad de agua, son un magnífico sustrato para el crecimiento de una gran diversidad de microorganismos. Como resultado de esto, se elaboran productos de baja y hasta de pésima calidad, lo cual se ve reflejada en la poca vida útil y la consiguiente devolución y/o reclamo por parte de los clientes. Además, ha generado un estancamiento en la economía ya que no es posible competir al menos con los mercados locales lo que genera decepciones y pérdidas a los pequeños empresarios.

La principal causa de deterioro de los alimentos es el ataque por diferentes tipos de microorganismos (bacterias, levaduras y mohos). El problema del deterioro microbiano de los alimentos tiene implicaciones económicas evidentes, tanto para los fabricantes (deterioro de materias primas y productos elaborados antes de su comercialización, pérdida de la imagen de marca, etc.) como para distribuidores y consumidores (deterioro de productos después de su adquisición y antes de su consumo).

La utilización de lisozima como conservante natural en la elaboración de productos lácteos, como son los quesos semi-maduros no solo permite optimizar la materia prima, sino también mantener productos y precios módicos en el mercado. objetivos:

Por lo anotado, en el presente trabajo se plantearon los siguientes

Utilizar la lisozima como conservante natural $(5,10$ y $15 \%)$, en reemplazo del conservante químico en la elaboración de quesos semimaduros en la planta de lácteos Molestina.

Evaluar las características Sensoriales, Físico - Químicas, y Microbiológicas de quesos semi-maduros con la utilización de lisozima como conservante natural.

Establecer el rendimiento del queso semi-maduro, cuando se utiliza la lisozima conservante natural.

Estimar la rentabilidad mediante el indicador beneficio / costo.

González (2002), manifiesta que la transformación de la leche en queso consta de fundamentalmente de dos procesos: la obtención de la cuajada y su maduración. Estos procesos a su vez se pueden dividir en tres fases esenciales:

La formación del gel de caseína, que es el cuajado o coagulación de la leche; la deshidratación parcial de este gel por sinéresis, es decir, por contracción de las micelas que la forman, el cual es el desuerado de la cuajada; y la maduración enzimática del gel deshidratado, el cual es el afinado o maduración de la cuajada, del que es responsable la proliferación de determinados microorganismos. 
Según Burdiles (2004), en la elaboración a los quesos se puede adicionar:

Cultivos de bacterias productoras de ácido láctico, cultivos de hongos o bacterias específicas para quesos de características especiales, cuajo u otras enzimas apropiadas para la coagulación, Cloruro de sodio, Agua, Cloruro de calcio, Nitrato de sodio o potasio (máximo $50 \mathrm{mg} / \mathrm{kg}$ de queso), Caroteno, carotenoides y riboflavina (solos o mezclados), sustancias aromatizantes o saborizantes naturales autorizadas.

La dosis máxima de los emulsionantes en el producto final será de 40 $\mathrm{g} / \mathrm{kg}$ (solos o mezclados) pero sin que los compuestos de fósforo agregados excedan de $9 \mathrm{~g} / \mathrm{kg}$ calculados como fósforo.

Por su parte Sánchez (2005), reporta que la coagulación de la leche se realiza con el cuajo, líquido procedente del $4^{\circ}$ estómago de rumiantes lactantes, o bien con cuajo sustitutivo, de origen vegetal, como el jugo de las hojas de la higuera, el galio o algunos tipos de cardos. Cuando la coagulación se realiza a $25^{\circ} \mathrm{C}$ o menos, se produce una coagulación débil cuyo resultado es una cuajada de aspecto irregular, propio para la fabricación de quesos de pasta blanda. Por el contrario, si la coagulación se realiza a $33^{\circ} \mathrm{C}$ o más, la cuajada es más compacta, formada por pequeños fragmentos del tamaño de un grano de arroz, y la temperatura habrá alcanzado durante la coagulación y de menor tamaño será el granulo. Cuando la cuajada ha adquirido la consistencia debida, se procede a la división en pequeños trozos, que una vez escurrido el suero, constituyen la pasta del queso.

Montenegro (2000), indica que la lisozima (EC 3.2.1.17), es una enzima que se encuentra ampliamente distribuida en la naturaleza y posee la capacidad de degradar la pared bacteriana por medio de la ruptura de los enlaces glucosídícos en el peptidoglicano bacteriano. La lisozima ha sido considerada como parte importante de un mecanismo primitivo de defensa en una gran variedad de organismos, los cuales carecen de un sistema inmunológico bien desarrollado, mientras que en organismos superiores la lisozima aparece en secreciones y tejidos mucosos con la función de protección bacteriana.

\section{Método}

La presente investigación se realizó en la Planta de Lácteos Molestina de la ESPE que pertenece a la Facultad de Ciencias Agropecuarias de la Escuela Superior Politécnica del Ejercito (IASA II), que se encuentra localizada en la Provincia de Santo Domingo de los Tsachilas, cantón Santo Domingo, km 28 vía a Quevedo, a una altitud de 270 m.s.n.m., con una latitud de 00¹8'43" y una longitud de 79018'43". El tiempo que duró el trabajo experimental fue de 120 días (4 meses), distribuidos en la elaboración 
de quesos semi-maduros, análisis bromatológicos, microbiológicos, organolépticos y la vida de anaquel del producto obtenido.

Para la elaboración del queso semi-maduro (Tipo Andino), se utilizaron 256 litros de leche, que se dividieron en 32 unidades experimentales, con un tamaño por unidad de 4 litros de leche, trabajándose dos unidades experimentales por semana, por efectos de producción.

Para la valoración de las características físico-químicas y microbiológicas se utilizaron muestras de $200 \mathrm{~g}$ de cada una de las repeticiones de los diferentes tratamientos experimentales, así como para las pruebas de aceptación del consumidor (características organolépticas).

Los materiales, equipos e instalaciones que se utilizaron fueron los siguientes:

Equipos y materiales de laboratorio, Acidómetro, Peachímetro, Tubos de ensayo, Termómetro, Calculadora, Equipo de protección personal (cofia, guantes, botas y mandil), En la elaboración de quesos semi-maduro.

Equipos: Olla doble fondo, Mesa de moldeo, Prensa.

Materiales: Bidón de 40 litros de acero inoxidable, Moldes para el queso, Baldes, Gavetas plásticas, Tina para salmuera, Frigorífico, Malla, Tacos de madera, Fuente de calor, Cilindro de gas, Balanza digital, Jabones, detergentes y desinfectantes, Libreta de apuntes.

Aditivos: Cloruro de Calcio, Fermento láctico, Ácido sórbico, Lisozima, Cuajo Marshall, Sal yodada.

Se evaluó el efecto de la utilización de distintos niveles de Lisozima como conservante natural $(5,10$ y $15 \%)$, en reemplazo del conservante químico (ácido sórbico E300), en la elaboración de queso tipo Andino (semimaduro) para ser comparada con un grupo testigo en el que se empleó el ácido sórbico, por lo que se contó con cuatro tratamientos experimentales, con cuatro repeticiones cada uno, en dos ensayos consecutivos, dando un total de 32 unidades experimentales, las mismas que fueron distribuidas bajo un diseño completamente al azar, en un arreglo combinatorio donde el Factor A, estuvo compuesto por los niveles de Lisozima y el Factor B, por los ensayos, por lo que para su análisis se ajustaron al siguiente modelo lineal aditivo (González, 2002):

$$
\mathrm{Yy}_{\mathrm{k}}=\mathrm{p}+\mathrm{Ai}+\mathrm{Bj}+\mathrm{Gy}_{\mathrm{k}}
$$

Donde: Y $y_{k}$ es el parámetro de determinación, $p$ es la media general, Ai es el efecto de los niveles de lisozima, Bj es el efecto del número de ensayo $\mathrm{Gy}_{\mathrm{k}}$ es el efecto del error experimental.

Los resultados experimentales fueron sometidos a las siguientes pruebas: Análisis de varianza (ADEVA) para las diferencias en las variables físico- químicas.

Separación de medias a través de la prueba de Waller-Duncan a los niveles de probabilidad $p<0.05$ y $p<0.01$. 
Prueba de Ratting Test, para las variables no paramétricas como son las variables organolépticas.

\section{Análisis de Resultados}

Las medias del contenido de proteína de los quesos fundidos no presentaron diferencias estadísticas $(p>0.05)$ por efecto de los niveles de Lisozima empleados, por cuanto se registraron contenidos de $26.33 \%$ cuando se utilizó el nivel $15 \%$ de lisozima (conservante natural), a $26.82 \%$ con el empleo del ácido sórbico (conservante químico), de igual manera entre ensayos tampoco se observaron diferencias estadísticas por cuanto los valores determinados fueron de 26.42 y $26.65 \%$ de proteína en los quesos del primero y segundo ensayos, respectivamente (gráfico 2); ratificándose por tanto que el reemplazo del conservante químico por el natural, no afecta las características nutritivas del queso, como se observa en la Figura 1, la función de estos productos es evitar el deterioro de los alimentos causado por el ataque de diferentes tipos de microorganismos (bacterias, levaduras, y mohos).

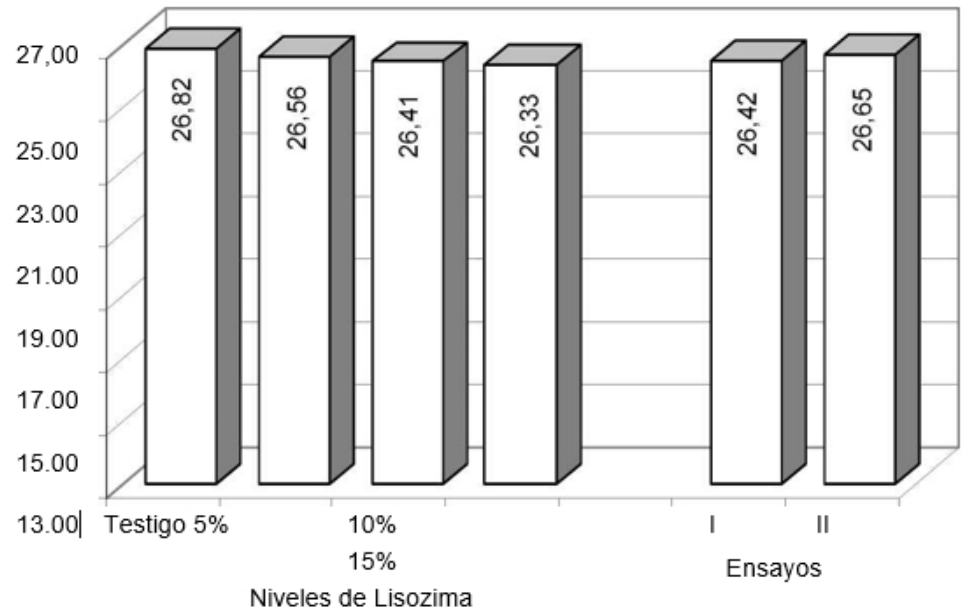

Figura 1. Contenido de Proteína (\%)

Las respuestas de la valoración organoléptica evaluadas a través de la Prueba de Ratting Test (para valores no paramétricos), permitió establecer que el empleo de los diferentes niveles de lisozima como conservante natural en reemplazo del conservante químico (ácido sórbico E300), no influyeron estadísticamente en las características organolépticas como se observan en la Tabla 1. 


\begin{tabular}{|c|c|c|c|c|c|c|c|}
\hline \multicolumn{8}{|c|}{$\begin{array}{c}\text { CONSERVANTE NATURAL EN REEMPLAZO DE CONSERVANTE QUIMICO (ȦCIDO SÖRBICO E300), EN LA PLANTA } \\
\text { Niveles de Lisozima } 5 \%\end{array}$} \\
\hline Parámetros & Testigo & $10 \%$ & & $15 \%$ & $\mathrm{~F} \&$ & Etab 005 & Signf \\
\hline Apariencia, 20 puntos & 18,13 & 18,38 & 17,75 & 17,75 & 0,643 & 4,90 & $\mathrm{~ns}$ \\
\hline Color, 20 puntos & 19,13 & 18,13 & 17,88 & 17,88 & 2,318 & 4,90 & ns \\
\hline Olor, 20 puntos & 18,38 & 18,50 & 17,88 & 17,63 & 0,891 & 4,90 & ns \\
\hline Sabor, 20 puntos & 17,00 & 16,50 & 17,25 & 17,75 & 1,857 & 4,90 & ns \\
\hline Acidez, 20 puntos & 16,88 & 15,88 & 16,00 & 16,00 & 0,665 & 4,90 & ns \\
\hline Total, 100 puntos & 89,50 & 87,38 & 86,75 & 87,00 & 0,892 & 4,90 & $\mathrm{~ns}$ \\
\hline Valoración 1 & MB & MB & MB & MB & & & \\
\hline
\end{tabular}

Tabla 1. Valoración organoléptica del queso andino elaborado con diferentes niveles lisozima como de lácteos Molestina.

\begin{tabular}{lc} 
1: Escala de valoración de calidad de productos alimenticios \\
\hline \multicolumn{2}{l}{ según Witting (1981). } \\
\hline Descripción de calidad & Puntaje \\
\hline Excelente & 100,00 \\
Muy bueno & 95,00 \\
Bueno & 85,00 \\
Regular & 75,00 \\
Límite no comestible & 65,00 \\
\hline
\end{tabular}

Tabla 2. Escala de valoración de calidad de productos alimenticios según Witting (1981).

Al realizar el análisis del beneficio/costo $(\mathrm{B} / \mathrm{C})$, mediante los costos de la leche e insumos utilizados, relacionándoles con los rendimientos obtenidos, y los ingresos percibidos, que se reportan en la Figura 2, se establece que el mayor beneficio/costo se alcanza al reemplazar el $15 \%$ del conservante químico con lisozima, ya que se determinó un $\mathrm{B} / \mathrm{C}$ de 1.13 , que representa que por cada dólar invertido se obtiene una utilidad de 13 centavos, o una rentabilidad del $13 \%$, que se reduce al $11 \%$ al emplearse niveles $11 \%$ con la utilización de 5 y $10 \%$ de lisozima, que son superiores a los beneficios económicos obtenidos al emplearse el conservante químico con el cual su rentabilidad alcanzó el $10 \%$ (B/C 1.10), notándose por consiguiente que al utilizar el $15 \%$ de lisozima se obtiene mayores rentabilidades económicas, en la producción y venta de quesos semimaduros, además de que presentan menos presencia microbiológica; además las rentabilidades alcanzadas son superiores a los que se generan a través de la banca privada, que pagan una tasa de interés hasta el $18 \%$ anual cuando se pone el capital a plazo fijo, en cambio que al invertir en estas actividades industriales se estaría generando una rentabilidad sobre el $156 \%$ anual, considerándose un mes del proceso. 


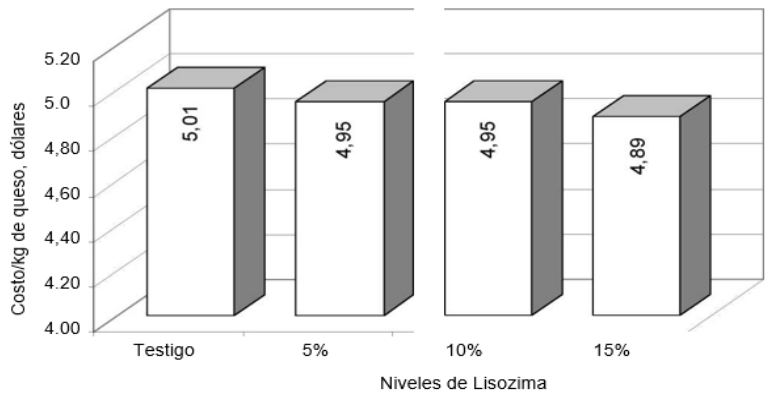

Figura 2. Relación Beneficio/costo

\section{Conclusiones}

El reemplazo del conservante químico con niveles de lisozima no afectó las propiedades físico-químicas del queso semi-maduro (Andino), presentando contenidos promedios del $37.46 \%$ de humedad, $26.53 \%$ de proteína, $25.53 \%$ de grasa y $5.65 \%$ de cenizas, con un $\mathrm{pH}$ ligeramente ácido (6.04).

La preferencia de los consumidores mediante la evaluación de las características organolépticas, determinan que no hubo diferencias entre los quesos elaborados con los niveles de lisozima en reemplazo del conservante químico, por cuanto las valoraciones totales fluctuaron entre 86.75 y 89.50 puntos, que de acuerdo a la escala propuesta por Witting, E. (1981), les corresponde a toda una calificación de Muy buena.

Los análisis microbiológicos iniciales determinaron la ausencia de coliformes totales, así como mohos y levaduras, en cambio a los 21 días de almacenamiento (vida de anaquel), se determinó que las cantidades registradas de estos microorganismos, disminuyen a medida que se incrementa los niveles de lisozima, presentando mejores respuestas el empleo del nivel $15 \%$.

Los mayores rendimientos (10.25\%), así como los menores costos de producción (4.89 USD por $\mathrm{kg}$ ), se obtuvieron cuando se elaboró el queso semi- maduro con el $15 \%$ de lisozima en reemplazo del conservante químico, por la que rentabilidad alcanzada es de $13 \%(\mathrm{~B} / \mathrm{C} 1.13)$, en un tiempo máximo de 30 días de proceso.

Utilizar en la elaboración de quesos semi-maduros (Andino), el $15 \%$ de lisozima.

\section{References:}

1. Burdiles, S. (2004). La leche y sus productos. Producción de leche.

2. González, M. (2002). Tecnología para la elaboración de queso blanco, amarillo y yogurt. Veraguas, Panamá. Archivo pdf. 
3. Montenegro, R. (2000). Propiedades bioquímicas y bacteriológicas de la lisozima de la almeja Tirela stuílorum. Facultad de Ciencias Marinas. Universidad Autónoma de Baja California. México. Ciencias Marinas, 26(2): 225-251.

4. Morales, A. (2004). La evaluación sensorial de los alimentos en teoría y en práctica. 1a ed. España, Madrid. Edit. Acribia. pp 26 - 31.

5. Paucar, S. (2006). Elaboración de queso fundido mediante la utilización de tres tipos de sales fundentes (citrato de sodio, citrato de calcio y citrato de potasio). Tesis de grado. Facultad de Ciencias Pecuaria, ESPOCH. Riobamba, Ecuador. pp. 45-60.

6. Pérez, A. (2001). Determinación del rendimiento y calidad en quesos semimaduros (Andino y Tilsit) al utilizar la leche de vacas Holstein frisian, Jersey y Brown swiss. Tesis de Grado. Facultad de Ciencias Pecuarias, Escuela Superior Politécnica de Chimborazo. Riobamba, Ecuador. pp 26-35.

7. Sánchez, J. (2005). El queso. sn. Lima, Perú. Edit. Infoalimentos. pp 10-32. 